\title{
KOMPARASI METODE AHP DAN MOORA DALAM PEMILIHAN JURUSAN PADA SMK TRI DHARMA 2 BOGOR
}

\author{
Sakinah Novianti Kartika Linggadewi ${ }^{1}$, Cahyani Budihartanti ${ }^{2}$ \\ Program Studi Sistem Informasi ${ }^{1}$, Program Studi Sistem Informasi ${ }^{2}$ \\ Sistem Informasi ${ }^{1}$, Sistem Informasi ${ }^{2}$ \\ STMIK Nusa Mandiri Jakarta ${ }^{1}$, STMIK Nusa Mandiri Jakarta ${ }^{2}$ \\ sakinahlingga10@gmail.com ${ }^{1}$, cahyani.cbh@nusamandiri.ac.id ${ }^{2}$
}

\begin{abstract}
ABSTRAK
Setiap tahun dilaksanakan penerimaan peserta didik baru dari jenjang Sekolah Menengah Pertama (SMP) ke Sekolah Menengah Kejuruan (SMK). Sesuai kurikulum yang berlaku di seluruh Indonesia, siswa kelas X SMK akan mengalami pemilihan jurusan (Penjurusan). Penjurusan ini diselenggarakan agar dapat menyesuaikan kemampuan siswa terhadap bidang yang dipilihnya. Dengan itu diharapkan kegiatan pembelajaran dapat berjalan dengan lancar tanpa mengalami kesulitan dan dapat meningkatkan prestasi belajar siswa. Sebaliknya, jika siswa kurang tepat dalam memilih jurusan akibatnya akan berkurangnya minat belajar dan menurunnya kualitas prestasi akademik siswa tersebut. Pada kenyataannya, ada beberapa siswa yang memilih jurusan tanpa mempertimbangkan minat dan bakatnya, terkadang siswa dipengaruhi oleh pendapat orangtua, teman atau figurfigur yang diidolakan. Tujuan dari penjurusan ini adalah untuk mengetahui faktor apa diantara minat, bakat, saran orangtua dan peluang karir yang dipilih oleh siswa dalam memilih jurusan pada SMK Tri Dharma 2 Bogor. Dengan menggunakan metode AHP dan MOORA sebagai model untuk uji komparasi hiearki. Metode ini digunakan karena dapat membantu dalam pengambilan keputusan dengan memperhatikan kriteria yang ada serta informasi yang diberikan bersifat kualitatif. Adapun hasil dari penelitian ini di dapat bahwa metode AHP dan MOORA dapat diterapkan dalam pengambilan keputusan pemilihan jurusan.
\end{abstract}

Kata kunci: Sistem Pendukung Keputusan, AHP, MOORA, Penjurusan.

Abstract: Every year new student admissions are carried out from junior high school to vocational high school. In accordance with the applicable curriculum throughout Indonesia, x grade vocational students will experience a selection of majors. This course is organized so that students can adjust their abilities to the chosen field. Hoped that learning activities can run smoothly without experiencing difficulties and can improve student learning achievement. Conversely, if students do not choose the right majors the result will be reduced interest in learning and decreased quality of academic achievement of these students. In fact, there are some students who choose majors without considering their interests, talents and career opportunities, sometimes students are influenced by the opinions of parents, friends or figures who are idolized. The purpose of this department is to find out what factors are among the interests, talents, parental advice and career opportunities chosen by students in choosing majors at SMK Tri Dharma 2 Bogor. By using the AHP and MOORA methods as a model for the comparison test hierarchy. This method is used because it can help in making decisions by considering existing criteria and the information provided is qualitative. The results of this study can be found that the AHP and MOORA methods can be applied in decision making in the selection of majors.

Keywords: Decision Support System, AHP, MOORA, Majors.

JISICOM (Journal of Information System, Informatics and Computing)

http://journal.stmikjayakarta.ac.id/index.php/jisicom Telp.+62-21-3905050, e-mail: jisicom@stmikjayakarta.ac.id, jisicom2017@gmail.com 


\section{PENDAHULUAN}

Setiap tahun dilaksanakan penerimaan peserta didik baru dari jenjang Sekolah Menengah Pertama (SMP) ke Sekolah Menengah Kejuruan (SMK). Sesuai kurikulum yang berlaku di seluruh Indonesia, siswa kelas X SMK akan mengalami pemilihan jurusan (Penjurusan). Jurusan yang tersedia di SMK Tri Dharma 2 Bogor meliputi, Keahlian Akuntansi (AK), Keahlian Administrasi Perkantoran (AP), Keahlian Pemasaran (PM), Keahlian Rekayasa Perangkat Lunak (RPL) dan Keahlian Multimedia (MM). Tujuan dari penjurusan ini yaitu agar siswa bisa lebih terarah dalam menerima pelajaran yang sesuai dengan minat dan bakat yang dimiliki oleh siswa[1].

Penjurusan ini diselenggarakan agar dapat menyesuaikan kemampuan siswa terhadap bidang yang dipilihnya. Kenyamanan dalam melakukan pembelajaran akan didapatkan jika penempatan penjurusan sesuai dengan minat dan bakat siswa. Dengan itu diharapkan kegiatan pembelajaran dapat berjalan dengan lancar tanpa mengalami kesulitan dan dapat meningkatkan prestasi belajar siswa. Sebaliknya, jika siswa kurang tepat dalam memilih jurusan akibatnya akan berkurangnya minat belajar dan menurunnya kualitas prestasi akademik siswa tersebut. Jelas ini sangat merugikan kedua belah pihak yaitu pihak siswa dan pihak sekolah[2].

Pada kenyataannya, ada beberapa siswa yang memilih jurusan tanpa mempertimbangkan minat dan bakatnya, terkadang siswa dipengaruhi oleh pendapat orangtua, teman atau figur-figur yang diidolakan[3]. Kesalahan dalam pemilihan jurusan tersebut dapat mengakibatkan kerugian finansial, waktu, dan kegagalan dalam belajar. Masalah pemilihan jurusan dapat mempengaruhi keseluruhan masa depannya. Oleh sebab itu, apabila siswa mampu memilih jurusan berdasarkan minat dan bakatnya serta berbagai pertimbangan yang menguntungkan, maka masa depan siswa akan lebih baik.

Pemilihan jurusan sangat dibutuhkan agar ilmu yang diperoleh dapat berguna bagi diri sendiri, keluarga, bangsa dan negara. Dimana untuk pemilihan jurusan ini dapat dipertimbangkan dengan Sistem Pendukung Keputusan (SPK)[4]. Sistem Pendukung Keputusan yang akan dirancang ini menggunakan metode Analytical Hierarchy Process (AHP) dan Multi-Objective Optimization by Ratio Analysis (MOORA). AHP merupakan metode yang memperhatikan faktor-faktor subyektifitas seperti persepsi, preferensi, pengalaman dan intuisi[5]. MOORA merupakan metode yang mudah dipahami dan fleksibel dalam memisahkan objek hingga proses evaluasi kriteria bobot keputusan6. Hasil yang diharapkan dari penelitian ini adalah untuk melihat apakah siswa sudah melakukan pemilihan jurusan sesuai dengan kriterianya masing-masing. Dari masalah tersebut maka penulis melakukan penelitian untuk menyelesaikan permasalahan yang terjadi dengan menganalisis suatu sistem yang menghasilkan sebuah informasi.

\section{METODE DAN MATERI}

\subsection{Metode Pengumpulan Data}

Ada beberapa metode pengumpulan data yang digunakan pada penelitian ini:

1. Pengumpulan Data Primer.

Pengumpulan data primer merupakan data yang telah diperoleh dari sumber pertama. Data ini belum dapat digunakan dan harus diolah terlebih dahulu untuk membuang unsur-unsur yang tidak penting[6]. Misalnya, data yang didapat dari kuesioner, pengumpulan data dengan alat mekanis dan sebagainya. Kuesioner disebarkan kepada para siswa-siswi SMK Tri Dharma 2 Bogor sedangkan wawancara dilakukan terhadap Bapak Kuswitiyarto, SE selaku Wakil Kepala Sekolah serta staf-staf yang bisa membantu memberikan informasi.

2. Pengumpulan Data Sekunder.

Pengumpulan data sekunder merupakan data yang telah dikumpulkan oleh pihak lain bukan oleh periset sendiri untuk tujuan yang lain. Ini mengandung arti bahwa periset sekadar mencatat, mengakses, atau meminta data tersebut (kadang sudah berbentuk informasi) ke pihak lain yang telah mengumpulkannya di lapangan. Periset hanya memanfaatkan data yang sudah ada untuk penelitiannya[7]. Biasanya sumber tidak langsung berupa data dokumentasi dan arsip-arsip resmi.

a. Populasi

Menurut Budiman[8], Populasi atau disebut juga universe adalah sekelompok individu atau obyek yang memiliki karakteristik sama, seperti sekelompok individu di masyarakat yang mempunyai umur, jenis kelamin, pekerjaan, status sosial yang sama, atau obyek lain yang mempunyai 
karakteristik sama seperti golongan darah $\mathrm{A}, \mathrm{AB}$, $\mathrm{B}$, dan $\mathrm{O}$.

Dalam penelitian ini, yang dimaksud populasi adalah para siswa dan siswi SMK Tri Dharma 2 Bogor yang dijadikan objek penyebaran kuesioner, serta Bapak Kuswitiyarto, SE selaku Wakil Kepala Sekolah serta staff-staf yang diwawancarai untuk memberikan informasi yang diperlukan dalam penulisan ini.

b. Sampel Penelitian

Menurut Dominikus[9], sampel adalah sebagian dari jumlah dan karakteristik yang dimiliki oleh populasi. Sampel penelitian adalah sebagian dari populasi yang diambil sebagai sumber data dan dapat mewakili seluruh populasi. Yang menjadi sampel penelitian ini adalah para siswa dan siswi yang memilih jurusan di SMK Tri Dharma 2 Bogor, diambil sebanyak 10 responden agar mewakili populasi secara keseluruhan.

c. Metode Analisis Data

Metode demi tercapainya tujuan dalam penelitian ini, maka digunakan metode analisis kuantitatif. Analisis kuantitatif dalam penelitian ini membandingkan kriteria dan alternatif yang bisa menghasilkan sebuah keputusan yaitu pemilihan jurusan pada calon siswa[10] dengan menggunakan metode AHP dan MOORA.

d. Analytical Hierarchy Process

Metode AHP merupakan teknik pengambilan keputusan/optimasi multivariate yang digunakan dalam analisis kebijaksanaan. Pada hakekatnya AHP merupakan suatu model pengambil keputusan yang komprehensif dengan memperhitungkan halhal yang bersifat kualitatif dan kuantitatif[10].

AHP umumnya digunakan dengan tujuan untuk menyusun prioritas dari berbagai alternatif pilihan yang ada dan pilihan-pilihan tersebut bersifat kompleks atau multi kriteria. Terdapat 4 aksiomaaksioma yang terkandung dalam model AHP:

1. Reciprocal Comparison artinya pengambilan keputusan harus dapat memuat perbandingan dan menyatakan preferensinya. Preferensi tersebut harus memenuhi syarat resiprokal yaitu apabila A lebih disukai daripada B dengan skala $\mathrm{x}$, maka $\mathrm{B}$ lebih disukai daripada A dengan skala 1 banding $\mathrm{x}$.

2. Homogenity artinya preferensi seseorang harus dapat dinyatakan dalam skala terbatas atau dengan kata lain elemen-elemennya dapat dibandingkan satu sama lainnya. Kalau aksioma ini tidak dipenuhi maka elemen-elemen yang dibandingkan tersebut tidak homogenity dan harus dibentuk cluster (kelompok elemen) yang baru.

3. Independence artinya preferensi dinyatakan dengan mengasumsikan bahwa kriteria tidak dipengaruhi oleh alternatif-alternatif yang ada melainkan oleh objektif keseluruhan. Ini menunjukkan bahwa pola ketergantungan dalam AHP adalah searah, maksudnya perbandingan antara elemen-elemen dalam satu tingkat dipengaruhi atau tergantung oleh elemen-elemen pada tingkat diatasnya.

4. Expectation artinya untuj tujuan pengambil keputusan. Struktur hirarki diasumsikan lengkap. Apabila asumsi ini tidak dipenuhi maka pengambil keputusan tidak memakai seluruh kriteria atau objektif yang tersedia atau diperlukan sehingga keputusan yang diambil dianggap tidak lengkap. Proses hirarki analitik (AHP) menyediakan kerangka yang memungkinkan untuk membuat suatu keputusan efektif atas isu kompleks dengan menyederhanakan dan mempercepat proses pendukung keputusan. Pada dasarnya AHP adalah suatu metode dalam merinci suatu situasi yang kompleks, yang terstruktur kedalam suatu komponen-komponennya. Artinya dengan menggunakan pendekatan AHP kita dapat memecahkan suatu masalah dalam pengambilan keputusan.

Prinsip kerja AHP adalah penyederhanaan suatu persoalan kompleks yang tidak terstruktur dan dinamik menjadi bagian-bagiannya, serta menata dalam suatu hierarki. Kemudian tingkat kepentingan setiap variabel diberi nilai dibandingkan dengan variabel lain. Dari berbagai pertimbangan tersebut kemudian dilakukan sintesa untuk menetapkan variabel yang memiliki prioritas tinggi dan berperan untuk mempengaruhi hasil pada sistem tersebut. Pada dasarnya langkahlangkah dalam metode AHP meliputi :

1. Membuat Hierarki

Persoalan yang akan diselesaikan, diuraikan menjadi unsur-unsurnya, yaitu kriteria dan alternatif, kemudian disusun menjadi struktur hierarki seperti Gambar II.1 berikut :

JISICOM (Journal of Information System, Informatics and Computing)

http://journal.stmikjayakarta.ac.id/index.php/jisicom Telp.+62-21-3905050, e-mail:jisicom@stmikjayakarta.ac.id, jisicom2017@gmail.com 


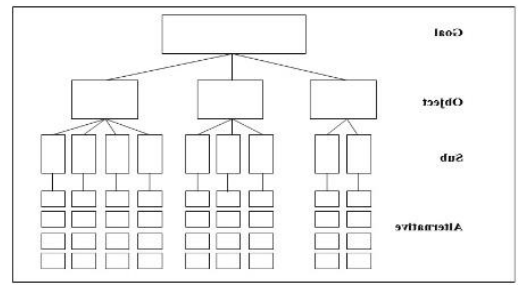

Sumber: Pratiwi (2016)

Gambar II.1 Struktur Hierarki AHP

2. Penilaian Kriteria dan Alternatif

Untuk berbagai persoalan yang ada, skala 1 sampai 9 adalah skala terbaik dalam mengekspresikan pendapat.

3. Penentuan Prioritas (Synthesis Of Priority)

Untuk setiap kriteria dan alternatif, perlu dilakukan perbandingan berpasangan (Pairwise Comparisons). Nilai-nilai perbandingan relatif kemudian diolah untuk menentukan peringkat alternatif dari seluruh alternatif. Baik kriteria kualitatif, maupun kriteria kuantitatif, dapat dibandingkan sesuai dengan penilaian yang telah ditentukan untuk menghasilkan bobot dan prioritas. Bobot atau prioritas dihitung dengan manipulasi matriks atau melalui penyelesaian persamaan matematik.

4. Konsistensi Logis (Logical Consistency)

Konsistensi memiliki dua makna. Pertama, objek-objek yang serupa bisa dikelompokkan sesuai dengan keseragaman dan relevansi. Kedua, menyangkut tingkat hubungan antar objek yang didasarkan pada kriteria tertentu.

Pada dasarnya prosedur atau langkah-langkah yang perlu diperhatikan dalam metode AHP, antara lain :

1. Mendefinisikan masalah dan menentukan solusi yang diinginkan.

2. Menentukan prioritas elemen.

3. Membuat perbandingan berpasangan, yaitu membandingkan elemen secara berpasangan sesuai kriteria yang diberikan.

4. Matriks bilangan berpasangan diisi menggunakan bilangan untuk mempresentasikan kepentingan relatif dari suatu elemen terhadap elemen yang lainnya.

5. Sintesis.

Pertimbangan - pertimbangan terhadap perbandingan berpasangan disintesis untuk memperoleh keseluruhan prioritas. Hal-hal yang dilakukan dalam langkah ini adalah : a). Menjumlahkan nilai-nilai dari setiap kolom pada matriks.

b). Membagi setiap nilai dari kolom dengan total kolom yang bersangkutan untuk memperoleh normalisasi matriks.

c). Menjumlahkan nilai-nilai dari setiap baris dan membaginya dengan jumlah elemen untuk mendapat nilai rata-rata.

d) Mengukur konsistensi

Dalam pembuatan keputusan, penting untuk mengetahui seberapa baik konsistensi yang ada karena kita tidak menginginkan keputusan berdasarkan pertimbangan dengan konsistensi yang rendah. Hal-hal yang dilakukan dalam pembuatan keputusan, langkah-langkahnya adalah :

1. Kalikan setiap nilai pada kolom pertama dengan prioritas relatif elemen pertama, nilai pada kolom kedua dengan prioritas relatif kedua, dan seterusnya.

2. Jumlahkan setiap baris.

3. Hasil dari penjumlahan baris dibagi dengan elemen prioritas relatif yang bersangkutan.

4. Jumlahkan hasil bagi diatas dengan banyaknya elemen yang ada, hasilnya disebut $\lambda$ maks.

5. Hitung Consistency Index (CI) dengan rumus:

$\mathrm{CI}=(\lambda$ maks $-\mathrm{n}) / \mathrm{n}-1$

Dimana $\mathrm{n}=$ banyaknya elemen berdasarkan sumber kriteria.

6. Hitung rasio konsistensi / Consistency Index dengan rumus:

$\mathrm{CR}=\mathrm{CI} / \mathrm{IR}$

Dimana $\mathrm{CR}=$ Consistency Ratio

"hasil akhir dari perhitungan"

$\mathrm{CI}=$ Consistency Index .

"untuk mencari konsistensi index"

$\mathrm{IR}=$ Index Random Consistency

7. Memeriksa konsistensi hierarki. Jika nilainya lebih dari $10 \%$ maka penilaian data judgement harus diperbaiki. Namun jika rasio konsistensi $(\mathrm{CI} / \mathrm{IR}) \leq 0,1$ maka hasil perhitungan bisa dinyatakan benar.

JISICOM (Journal of Information System, Informatics and Computing)

http://journal.stmikjayakarta.ac.id/index.php/jisicom Telp.+62-21-3905050, e-mail:jisicom@stmikjayakarta.ac.id, jisicom2017@gmail.com 
Tabel II.1. Konsistensi Hierarki

\begin{tabular}{|c|c|}
\hline Ukuran matriks & Nilai $\mathbb{R}$ \\
\hline 1,2 & 0,00 \\
\hline 3 & 0,58 \\
\hline 4 & 0,90 \\
\hline 5 & 1,12 \\
\hline 6 & 1,24 \\
\hline 7 & 1,32 \\
\hline 8 & 1,41 \\
\hline 9 & 1,45 \\
\hline 10 & 1,49 \\
\hline 11 & 1,51 \\
\hline 12 & 1,48 \\
\hline 13 & 1,56 \\
\hline 14 & 1,57 \\
\hline 15 & 1,59 \\
\hline
\end{tabular}

Sumber : Pratiwi (2016)

e. Multi Objective Optimization by Ratio Analysis (MOORA) .

Metode MOORA[11] adalah multiobjektif sistem yang mengoptimalkan dua atau lebih attribut yang saling bertentangan secara bersamaan. Metode ini diterapkan untuk memecahkan masalah dengan perhitungan matematika yang kompleks.

Langkah-langkah dalam metode MOORA adalah sebagai berikut:

1. Penentuan nilai matrik

Menentukan Tujuan untuk mengindentifikasi atribut evaluasi yang bersangkutan

2. Normalisasi matriks

Mewakilkan semua informasi yang tersedia untuk setiap atrribut dalam bentuk matriks keputusan.

$$
\mathrm{X}=\left[\begin{array}{lll}
x_{11} & x_{m 1} & x_{1 n} \\
x_{21} & x_{22} & x_{2 n} \\
x_{m 1} & x_{m 2} & x_{m n}
\end{array}\right]
$$

3. Normalisasi matriks Breaures (2008) menyimpulkan bahwa untuk penyebut, pilihan terbaik adalah akar kuadrat dari jumlah kuadrat dan setiap alternatif peratribut.

$$
X_{i j}^{*} \frac{X_{i j}}{\sqrt{\left[\sum_{i=1}^{m} X_{i j}^{2}\right]}}
$$

Untuk $\mathrm{j}=12 \ldots \mathrm{m}$

4. Mengoptimalkan Atribut

Untuk optimasi Multiobjektif, ukuran yang dinormalisasi ditambahkan dalam kasus maksimasi (untuk atribut yang menguntungkan) dan dikurangi dalam kasus minimasi (untuk atribut yang tidak menguntungkan).

$$
Y_{i} \sum_{j=1}^{g} W_{j}-\sum_{j=g+1}^{n} W_{j} W_{i j}^{*}
$$

Dimana $G$ adalah jumlah atribut yang akan dimaksimalkan, (n-g) adalah jumlah atribut yang akan diminimalkan, dan yi adalah nilai penilaian yang telah dinormalisasikan dari altenatif 1 terhadap semua atribut. Saat atribut bobot dipertimbangkan, persamaan 3 menjadi sebagai berikut

$$
\mathrm{Yi}=\sum_{j=1}^{g} W_{j} \mathrm{X} * \mathrm{Ij}-\sum_{j=g+1}^{n} W_{j} W_{i j}^{*}
$$

$\mathrm{Wj}$ adalah bobot dari Jth atribut, yang dapat ditentukan dengan menerapkan applying analtic hieararchy process (AHP) atau metode entrophy.

5. Perangkingan nilai $Y$

Nilai Yi bisa positif atau negatif tergantung dari total maksimak dan minimal dalam matriks keputusan. Sebuah urutan peringkat dan Yi menujukan pilihan terakhir.

Alternatif terbaik memiliki nilai Yi tertinggi, sedangkan alternatif terburuk memiliki nilai yang rendah.

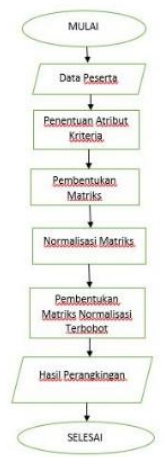

Sumber Olah Data (2020)

Gambar II.2 Tahapan Metode MOORA

2.2. Kriteria-kriteria Dan Alternatif-alternatif Pemilihan Jurusan

Dalam menentukan pemilihan jurusan perkuliahaan, ada beberapa kriteria yang digunakan, berikut daftar kriteria-kriterianya:

1. Minat

Peneliti menggunakan minat sebagai salah satu kriteria, untuk mengetahui apakah hipotesa minat mempunyai pengaruh dalam pengambilan

JISICOM (Journal of Information System, Informatics and Computing)

http://journal.stmikjayakarta.ac.id/index.php/jisicom Telp.+62-21-3905050, e-mail:jisicom@stmikjayakarta.ac.id, jisicom2017@gmail.com 


\section{Journal of Information System, Informatics and Computing}

keputusan calon siswa dalam memilih jurusan tersebut.

2. Bakat

Peneliti menggunakan bakat sebagai salah satu kriteria, untuk mengetahui apakah hipotesa bakat mempunyai pengaruh dalam pengambilan keputusan calon siswa dalam memilih jurusan tersebut.

3. Kualitas Jurusan

Peneliti menggunakan kualitas jurusan sebagai salah satu kriteria, untuk mengetahui apakah hipotesa kualitas jurusan mempunyai pengaruh dalam pengambilan keputusan calon siswa dalam memilih jurusan tersebut.

4. Peluang Karir

Peneliti menggunakan peluang karira sebagai salah satu kriteria, untuk mengetahui apakah hipotesa peluang karir mempunyai pengaruh dalam pengambilan keputusan calon siswa dalam memilih jurusan.

Sedangkan ada pula beberapa alternatif yang akan digunakan yaitu :

1. AP (Administrasi Perkantoran)

2. MM (Multimedia)

3. RPL (Rekayasa Perangkat Lunak)

\section{PEMBAHASAN DAN HASIL}

\subsection{Perhitungan Menggunakan Metode AHP}

Pada tahapan ini akan dijelaskan mengenai proses perhitungan dengan menggunakan metode AHP dalam pengambilan keputusan pemilihan jurusan pada SMK Tri Dharma 2 Bogor.

a. Matriks Faktor Pembobotan Total Dari Kriteria

Pada tahap ini membuat pembobotan total sesuai dengan kriteria dan alternatif yang telah ditentukan maka didapat tabel sebagai berikut :

1. Matriks Faktor Pembobotan Total Dari Kriteria Utama

Pada tabel III.1, ditampilkan matriks pembobotan total kriteria utama.

Tabel III.1 Matriks Pembobotan Total Kriteria Utama

\begin{tabular}{|l|l|l|l|l|l|l|r|}
\hline Kriteria & R1 & R2 & R3 & R4 & R10 & Kriteria & Geomean \\
\hline Minat & 5,0000 & 7,0000 & 0,2000 & 9,0000 & 9,0000 & Bakat & 4,1426 \\
\hline Minat & 0,1429 & 9,0000 & 9,0000 & 0,1111 & 0,1429 & Orangtua & 0,6776 \\
\hline Minat & 5,0000 & 0,1429 & 0,2000 & 0,1111 & 0,1429 & Peluang Karir & 0,3138 \\
\hline Bakat & 0,1429 & 5,0000 & 1,0000 & 0,1111 & 0,1429 & Orangtua & 0,3415 \\
\hline Bakat & 3,0000 & 0,1429 & 0,1111 & 0,1111 & 0,1429 & Peluang Karir & 0,2671 \\
\hline $\begin{array}{l}\text { Saran } \\
\text { Orangtua }\end{array}$ & 7,0000 & 0,1111 & 0,2000 & 0,1111 & 0,1429 & Peluang Karir & 0,4789 \\
\hline
\end{tabular}

Sumber: Olah Data (2020)

2. Matriks Faktor Pembobotan Total Dari Alternatif dan Kriteria Minat

Pada tabel III.2, ditampilkan matriks pembobotan alternatif dan kriteria minat.

Tabel III.2 Matriks Pembobotan Total Alternatif dan Kriteria Minat

\begin{tabular}{|l|l|l|l|l|l|l|r|}
\hline Alternatif & R1 & R2 & R3 & R4 & R10 & Kriteria & Geomean \\
\hline AP & 0,2000 & 7,0000 & 0,3333 & 0,2000 & 0,3333 & MM & 0,8366 \\
\hline AP & 0,3333 & 7,0000 & 0,1429 & 0,1429 & 0,1429 & RPL & 0,5769 \\
\hline MM & 7,0000 & 0,2000 & 0,1429 & 0,1429 & 0,1429 & RPL & 0,9349 \\
\hline
\end{tabular}

Sumber: Olah Data (2020)

3. Matriks Faktor Pembobotan Total Dari Alternatif dan Kriteria Bakat.

Pada tabel III.3, ditampilkan matriks pembobotan alternatif dan kriteria bakat.

Tabel III.3 Matriks Pembobotan Total Alternatif dan Kriteria Bakat

\begin{tabular}{|l|l|l|l|l|l|l|r|}
\hline Alternatif & R1 & R2 & R3 & R4 & R10 & Kriteria & Geomean \\
\hline AP & 0,3333 & 7,0000 & 0,3333 & 0,3333 & 0,2000 & MM & 0,9036 \\
\hline AP & 1,0000 & 7,0000 & 0,2000 & 0,2000 & 0,1429 & RPL & 0,7310 \\
\hline MM & 3,0000 & 0,2000 & 0,2000 & 0,2000 & 0,1429 & RPL & 0,9029 \\
\hline
\end{tabular}

Sumber : Olah Data (2020)

4. Matriks Faktor Pembobotan Total Dari Alternatif dan Kriteria Saran Orangtua

Pada tabel III.4, ditampilkan matriks pembobotan alternatif dan kriteria Saran Orangtua.

Tabel III.4 Matriks Pembobotan Total Alternatif dan Kriteria Saran Orangtua

\begin{tabular}{|l|l|l|l|l|l|l|r|}
\hline Alternatif & R1 & R2 & R3 & R4 & R10 & Kriteria & Geomean \\
\hline AP & 0,1111 & 9,0000 & 0,3333 & 0,2000 & 0,2000 & MM & 0,7068 \\
\hline AP & 0,3333 & 9,0000 & 0,2000 & 0,1111 & 0,1111 & RPL & 0,5350 \\
\hline MM & 9,0000 & 0,1429 & 0,2000 & 0,1111 & 0,1111 & RPL & 0,8960 \\
\hline
\end{tabular}

Sumber : Olah Data (2020)

JISICOM (Journal of Information System, Informatics and Computing)

http://journal.stmikjayakarta.ac.id/index.php/jisicom Telp.+62-21-3905050, e-mail:jisicom@stmikjayakarta.ac.id, jisicom2017@gmail.com 
5. Matriks Faktor Pembobotan Total Dari Alternatif dan Kriteria Peluang Karir

Pada tabel III.5, ditampilkan matriks pembobotan alternatif dan kriteria peluang karir.

Tabel III.5 Matriks Pembobotan Total Alternatif dan Kriteria Peluang Karir

\begin{tabular}{|l|l|l|l|l|l|l|r|}
\hline Alternatif & R1 & R2 & R3 & R4 & R10 & Rriteria & Geomean \\
\hline AP & 0,1429 & 9,0000 & 0,3333 & 0,2000 & 0,1429 & MM & 0,7755 \\
\hline AP & 0,2000 & 9,0000 & 0,1111 & 0,1111 & 0,1111 & RPL & 0,5079 \\
\hline MM & 1,0000 & 0,2000 & 0,1111 & 0,1111 & 0,1111 & RPL & 0,7569 \\
\hline
\end{tabular}

Sumber : Olah Data (2020)

b. Matriks Perbandingan Berpasangan (Pairwise Comparison).

Pada tahap ini membuat perbandingan elemen secara berpasangan sesuai dengan kriteria dan alternatif yang telah ditentukan maka didapat tabel matriks perbandingan antar kriteria dan matriks perbandingan antar alternatif.

1. Matriks Perbandingan Berpasangan Kriteria

Pada tabel III.6, ditampilkan matriks perbandingan berpasangan kriteria.

Tabel III.6 Matriks Perbandingan Berpasangan Kriteria.

\begin{tabular}{|l|c|c|c|c|}
\hline Kriteria & Minat & Bakat & Saran Orangtua & Peluang Karir \\
\hline Minat & 1,0000 & 4,1426 & 0,6776 & 0,3138 \\
\hline Bakat & 0,2414 & 1,0000 & 0,3415 & 0,2671 \\
\hline Saran Orangtua & 1,4758 & 2,9279 & 1,0000 & 0,4789 \\
\hline Peluang Karir & 3,1868 & 3,7433 & 2,0880 & 1,0000 \\
\hline Jumlah & 5,9040 & 11,8139 & 4,1071 & 2,0599 \\
\hline
\end{tabular}

Sumber: Olah Data (2020)

2. Matriks Perbandingan Berpasangan Alternatif pada Kriteria Minat.

Pada tabel III.7, ditampilkan matriks perbandingan berpasangan Alternatif pada kriteria minat.

Tabel III.7 Matriks Perbandingan Berpasangan Alternatif pada Kriteria Minat.

\begin{tabular}{|c|c|c|c|}
\hline Alternatif & AP & MM & RPL \\
\hline AP & 1,0000 & 0,8366 & 0,5769 \\
\hline MM & 1,1953 & 1,0000 & 0,9349 \\
\hline RPL & 1,7335 & 1,0696 & 1,0000 \\
\hline Jumlah & 3,9287 & 2,9062 & 2,5118 \\
\hline
\end{tabular}

Sumber: Olah Data (2020)

3. Matriks Perbandingan Berpasangan Alternatif pada Kriteria Bakat.

Pada tabel III.8, ditampilkan matriks perbandingan berpasangan Alternatif pada kriteria bakat.

Tabel III.8 Matriks Perbandingan Berpasangan Alternatif pada Kriteria Bakat

\begin{tabular}{|c|c|c|c|}
\hline Alternatif & AP & MM & RPL \\
\hline AP & 1,0000 & 0,9036 & 0,7310 \\
\hline MM & 1,1067 & 1,0000 & 0,9029 \\
\hline RPL & 1,3680 & 1,1076 & 1,0000 \\
\hline Jumlah & 3,4747 & 3,0112 & 2,6339 \\
\hline
\end{tabular}

Sumber : Olah Data (2020)

4. Matriks Perbandingan Berpasangan Alternatif pada Kriteria Saran Orangtua.

Pada tabel III.9, ditampilkan matriks perbandingan berpasangan Alternatif pada kriteria Saran Orangtua.

Tabel III.9

Matriks Perbandingan Berpasangan Alternatif Kriteria Saran Orangtua

\begin{tabular}{|c|c|c|c|}
\hline Alternatif & AP & MM & RPL \\
\hline AP & 1,0000 & 0,7068 & 0,5350 \\
\hline MM & 1,4148 & 1,0000 & 0,8960 \\
\hline RPL & 1,8692 & 1,1161 & 1,0000 \\
\hline Jumlah & 4,2841 & 2,8229 & 2,4309 \\
\hline
\end{tabular}

Sumber : Olah Data (2020)

5. Matriks Perbandingan Berpasangan Alternatif pada Kriteria Peluang Karir.

Pada tabel III.10, ditampilkan matriks perbandingan berpasangan Alternatif pada kriteria Peluang Karir.

Tabel III.10

Matriks Perbandingan Berpasangan Alternatif Kriteria Peluang Karir

\begin{tabular}{l|r|r|c|}
\hline Alternatif & AP & MM & RPL \\
\hline AP & 1,0000 & 0,7755 & 0,5079 \\
\hline MM & 1,2894 & 1,0000 & 0,7569 \\
\hline RPL & 1,9688 & 1,3211 & 1,0000 \\
\hline Jumlah & 4,2582 & 3,0967 & 2,2648 \\
\hline
\end{tabular}

Sumber : Olah Data (2020)

c. Matriks Faktor Pembobotan Hierarki Kriteria Yang Dinormalisasikan.

Pada tahap ini membuat pembobotan hierarki yang dinormalisasikan sesuai dengan kriteria dan alternatif yang telah ditentukan maka didapat tabel sebagai berikut:

1. Matriks Faktor Pembobotan Hierarki Kriteria Yang Dinormalisasikan.

Pada tabel III.11, ditampilkan matriks pembobotan hierarki kriteria yang dinormalisasikan.

Tabel III.11

Matriks Pembobotan Hierarki Kriteria Yang Dinormalisasikan. 


\begin{tabular}{|l|c|c|c|c|c|}
\hline Kriteria & Minat & Bakat & Saran Orangtua & Peluang Karir & Eigen Vektor \\
\hline Minat & 0,1694 & 0,3507 & 0,1650 & 0,1523 & 0,2093 \\
\hline Bakat & 0,0409 & 0,0846 & 0,0832 & 0,1297 & 0,0846 \\
\hline Saran Orangtua & 0,2500 & 0,2478 & 0,2435 & 0,2325 & 0,2434 \\
\hline Peluang Karir & 0,5398 & 0,3169 & 0,5084 & 0,4855 & 0,4626 \\
\hline Jumlah & & \multicolumn{5}{|l|}{} & 1,0000 \\
\hline
\end{tabular}

Sumber : Olah Data (2020)

Berdasarkan tabel III.11, maka didapat nilai ratarata masing-masing kriteria minat bernilai 0.2093, bakat bernilai 0.0846 , saran orangtua bernilai 0,2434 dan untuk peluang karir bernilai 0.4626 .

2. Matriks Faktor Pembobotan Hierarki Kriteria Minat Yang Dinormalisasikan

Pada tabel III.12, ditampilkan matriks pembobotan hierarki kriteria minat yang dinormalisasikan.

Tabel III.12

Matriks Pembobotan Hierarki Kriteria Minat Yang Dinormalisasikan

\begin{tabular}{|l|l|l|l|l|}
\hline Alternatif & AP & MM & RPL & Eigen Vektor \\
\hline AP & 0,2545 & 0,2879 & 0,2297 & 0,2574 \\
\hline MM & 0,3042 & 0,3441 & 0,3722 & 0,3402 \\
\hline RPL & 0,4412 & 0,3680 & 0,3981 & 0,4025 \\
\hline Jumlah & \multicolumn{4}{|l}{} \\
\hline
\end{tabular}

Sumber : Olah Data (2020)

3. Matriks Faktor Pembobotan Hierarki Kriteria Bakat Yang Dinormalisasikan

Pada tabel III.13, ditampilkan matriks pembobotan hierarki kriteria bakat yang dinormalisasikan.

Tabel III.13

Matriks Pembobotan Hierarki Kriteria Bakat Yang Dinormalisasikan

\begin{tabular}{|l|c|c|c|c|}
\hline Alternatif & AP & MM & RPL & Eigen Vektor \\
\hline AP & 0,2878 & 0,3001 & 0,2775 & 0,2885 \\
\hline MM & 0,3185 & 0,3321 & 0,3428 & 0,3311 \\
\hline RPL & 0,3937 & 0,3678 & 0,3797 & 0,3804 \\
\hline Jumlah & \multicolumn{4}{|l}{} \\
\hline
\end{tabular}

Sumber : Olah Data (2020)

4. Matriks Faktor Pembobotan Hierarki Kriteria Saran Orangtua Yang Dinormalisasikan

Pada tabel III.14, ditampilkan matriks pembobotan hierarki kriteria saran orangtua yang dinormalisasikan.

Tabel III.14

Matriks Pembobotan Hierarki Kriteria Saran Orangtua Yang Dinormalisasikan

\begin{tabular}{|l|l|l|l|c|}
\hline Alternatif & AP & MM & RPL & Eigen Vektor \\
\hline AP & 0,2334 & 0,2504 & 0,2201 & 0,2346 \\
\hline MM & 0,3303 & 0,3542 & 0,3686 & 0,3510 \\
\hline RPL & 0,4363 & 0,3954 & 0,4114 & 0,4144 \\
\hline Jumlah & \multicolumn{4}{|l}{} \\
\hline
\end{tabular}

Sumber : Olah Data (2020)

5. Matriks Faktor Pembobotan Hierarki Kriteria Peluang Karir Yang Dinormalisasikan

Pada tabel III.15, ditampilkan matriks pembobotan hierarki kriteria peluang karir yang dinormalisasikan.

Tabel III.15

Matriks Pembobotan Hierarki Kriteria Peluang Karir Yang Dinormalisasikan

\begin{tabular}{|l|l|l|c|c|}
\hline Alternatif & AP & MM & RPL & Eigen Vektor \\
\hline AP & 0,2348 & 0,2504 & 0,2243 & 0,2365 \\
\hline MM & 0,3028 & 0,3229 & 0,3342 & 0,3200 \\
\hline RPL & 0,4624 & 0,4266 & 0,4415 & 0,4435 \\
\hline Jumlah & \multicolumn{4}{|l}{} \\
\hline
\end{tabular}

Sumber : Olah Data(2020)

d. Menentukan Nilai CI dan CR

Penilaian terhadap perbandingan dianggap konsisten dengan ketentuan jika nilai CR (Consistency Random) tidak lebih dari 0,1 sehingga penilaian perbandingan kriteria penentuan pemilihan jurusan sudah konsisten. Sebelum menentukan nilai CI dan CR harus terlebih dahulu menentukan nilai Lamda Max.

Menentukan nilai CI dan CR antar kriteria

$$
\begin{aligned}
\lambda \max & =(5,9040 * 0,2093) \\
& +(11,8139 * 0,0846) \\
& +(4,1071 * 0,2434) \\
& +(2,0599 * 0,4626)=4,1881 \\
C I & =\frac{(\lambda \text { maks }-\mathrm{n})}{\mathrm{n}-1} \\
= & \frac{(4,1881-4)}{4-1} \\
& =0,0627 \\
& C R=\frac{C I}{R I} \\
& =\frac{0,0627}{0,9} \\
& =0,0697
\end{aligned}
$$

Berdasarkan perhitungan diatas didapat nilai untuk CR sebesar 0,0697 maka penilaian perbandingan dianggap konsisten karena CR tidak lebih dari 0,1 .

Menentukan nilai CI dan CR kriteria minat pada alternatif. 


$$
\begin{aligned}
& \lambda \max =(3,9287* 0,2574)+(2,9062 * 0,3402) \\
&+(2,5118 * 0,4025) \\
&=3,0106 \\
& C I= \frac{(\lambda \operatorname{maks}-\mathrm{n})}{\mathrm{n}-1} \\
&= \frac{(3,0106-3)}{3-1} \\
&= 0,0053 \\
& C R=\frac{C I}{R I} \\
&= \frac{0,0053}{0,58} \\
&=0,0092
\end{aligned}
$$

Berdasarkan perhitungan diatas didapat nilai untuk CR sebesar 0,0092 maka penilaian perbandingan dianggap konsisten karena CR tidak lebih dari 0,1 .

Menentukan nilai CI dan CR kriteria bakat pada alternatif

$$
\begin{aligned}
& \lambda \max =(3,4747* 0,2885)+(3,0112 * 0,3311) \\
&+(2,6339 * 0,3804) \\
&=3,0014 \\
& C I= \frac{(\lambda \operatorname{maks}-\mathrm{n})}{\mathrm{n}-1} \\
&= \frac{(3,0014-3)}{3-1} \\
&= 0,0007 \\
& C R=\frac{C I}{R I} \\
&= \frac{0,0007}{0,58} \\
&= 0,0012
\end{aligned}
$$

Berdasarkan perhitungan diatas didapat nilai untuk CR sebesar 0,0012 maka penilaian perbandingan dianggap konsisten karena CR tidak lebih dari 0,1 .

Menentukan nilai CI dan CR kriteria saran orangtua pada alternatif

$$
\begin{aligned}
\lambda \max =(4,2841 & * 0,2346)+(2,8229 * 0,3510) \\
+ & (2,4309 * 0,4144) \\
& =3,0033 \\
C I & =\frac{(\lambda \operatorname{maks}-\mathrm{n})}{\mathrm{n}-1} \\
= & \frac{(3,0033-3)}{3-1} \\
& =0,0017 \\
& C R=\frac{C I}{R I} \\
& =\frac{0,0017}{0,58} \\
& =0,0029
\end{aligned}
$$

Berdasarkan perhitungan diatas didapat nilai untuk CR sebesar 0,0029 maka penilaian perbandingan dianggap konsisten karena CR tidak lebih dari 0,1 .

Menentukan nilai CI dan CR kriteria peluang karir pada alternatif

$$
\begin{aligned}
& \lambda \max =(4,2582* 0,2365)+(3,0967 * 0,3200) \\
&+(2,2648 * 0,4435) \\
&=3,0025 \\
& C I= \frac{(\lambda \operatorname{maks}-\mathrm{n})}{\mathrm{n}-1} \\
&= \frac{(3,0025-3)}{3-1} \\
&= 0,0012 \\
& C R=\frac{C I}{R I} \\
&= \frac{0,0012}{0,58} \\
&= 0,0021
\end{aligned}
$$

Berdasarkan perhitungan diatas didapat nilai untuk CR sebesar 0,0021 maka penilaian perbandingan dianggap konsisten karena CR tidak lebih dari 0,1 .

e. Menentukan Matriks Hubungan Antara Kriteria dan Alternatif

Dari hasil evaluasi keempat kriteria yaitu minat, bakat, saran orangtua dan peluang karir dikalikan dengan eigen vector maka akan diperoleh hubungan antara kriteria dan alternatif sebagai berikut :

Tabel III.16 Matriks Hubungan Antara Kriteria Dan Alternatif

\begin{tabular}{|l|r|r|c|c|c|}
\hline Goal & Minat & Bakat & Saran Orangtua & Peluang Karir & Total \\
\hline$\%$ & $21 \%$ & $8 \%$ & $24 \%$ & $46 \%$ & $100 \%$ \\
\hline AP & 0,0539 & 0,0244 & 0,0571 & 0,1094 & $24 \%$ \\
\hline MM & 0,0712 & 0,0280 & 0,0855 & 0,1480 & $33 \%$ \\
\hline RPL & 0,0843 & 0,0322 & 0,1009 & 0,2052 & $42 \%$ \\
\hline \multicolumn{7}{|c|}{ Total } & $100 \%$ \\
\hline
\end{tabular}

Sumber : Olah Data (2020)

f. Menentukan Matriks Prioritas Berdasarkan Alternatif

Dan untuk total rangking yang didapat melalui hasil perkalian faktor evaluasi masing-masing alternatif dengan faktor bobot sebagai berikut :

Tabel III.17 Matriks Prioritas Berdasarkan Alternatif AP 


\section{Journal of Information System, Informatics and Computing}

\begin{tabular}{|c|c|c|c|c|c|c|c|}
\hline \multirow[b]{2}{*}{ Alternatif } & \multirow[b]{2}{*}{ Kriteria } & \multirow{2}{*}{$\begin{array}{c}\text { Perbandingan } \\
\text { Faktor Antar } \\
\text { Kriteria }\end{array}$} & \multirow{2}{*}{$\begin{array}{c}\text { Perbandingan } \\
\text { Faktor Antar } \\
\text { Alternatif }\end{array}$} & \multirow[b]{2}{*}{ Aggregate } & \multicolumn{2}{|c|}{ Peringkat } & \multirow[b]{2}{*}{$\%$} \\
\hline & & & & & Kriteria & Alternatif & \\
\hline \multirow{5}{*}{ AP } & Minat & 0,2093 & 0,2574 & 0,0539 & 3 & \multirow{5}{*}{3} & \multirow{5}{*}{$24 \%$} \\
\hline & Bakat & 0,0846 & 0,2885 & 0,0244 & 4 & & \\
\hline & $\begin{array}{l}\text { Saran } \\
\text { Orangtua }\end{array}$ & 0,2434 & 0,2346 & 0,0571 & 2 & & \\
\hline & Peluang & & & & & & \\
\hline & Karir & 0,4626 & 0,2365 & 0,1094 & 1 & & \\
\hline \multicolumn{2}{|c|}{ Total } & 1,0000 & 1,0170 & 0,2448 & & & \\
\hline
\end{tabular}

Sumber : Olah Data(2020)

Tabel III.18 Matriks Prioritas Berdasarkan Alternatif MM

\begin{tabular}{|c|c|c|c|c|c|c|c|}
\hline \multirow{2}{*}{ Alternatif } & \multirow{2}{*}{ Kriteria } & \multirow{2}{*}{$\begin{array}{c}\text { Perbandingan } \\
\text { Faktor Antar } \\
\text { Kriteria }\end{array}$} & \multirow{2}{*}{$\begin{array}{c}\text { Perbandingan } \\
\text { Faktor Antar } \\
\text { Alternatif }\end{array}$} & \multirow{2}{*}{ Aggregate } & \multicolumn{2}{|c|}{ Peringkat } & \multirow[b]{2}{*}{$\%$} \\
\hline & & & & & Kriteria & Alternatif & \\
\hline \multirow{5}{*}{ MM } & Minat & 0,2093 & 0,3402 & 0,0712 & 3 & \multirow{5}{*}{2} & \multirow{5}{*}{$33 \%$} \\
\hline & Bakat & 0,0846 & 0,3311 & 0,0280 & 4 & & \\
\hline & $\begin{array}{c}\text { Saran } \\
\text { Orangtua }\end{array}$ & 0,2434 & 0,3510 & 0,0855 & 2 & & \\
\hline & Peluang & & & & & & \\
\hline & Karir & 0,4626 & 0,3200 & 0,1480 & 1 & & \\
\hline \multicolumn{2}{|c|}{ Total } & 1,0000 & 1,3423 & 0,3327 & & & \\
\hline
\end{tabular}

Sumber : Olah Data (2020)

Tabel III.19 Matriks Prioritas Berdasarkan Alternatif RPL

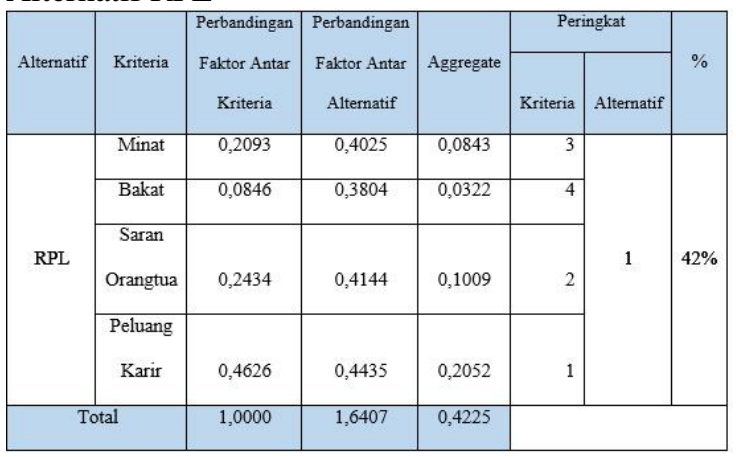

Sumber : Olah Data (2020)

g. Proses Perangkingan

Tabel III.20 Proses Perangkingan

\begin{tabular}{|c|c|c|c|c|c|c|c|}
\hline \multicolumn{4}{|c|}{ Peringkat Kriteria } & \multicolumn{3}{|c|}{ Peringkat Alternatif } \\
\hline 1 & Peluang Karir & 0,4626 & $46 \%$ & 1 & RPL & 0,4225 & $42 \%$ \\
\hline 2 & Saran Orangtua & 0,2434 & $24 \%$ & 2 & MM & 0,3327 & $33 \%$ \\
\hline 3 & Minat & 0,2093 & $21 \%$ & 3 & AP & 0,2448 & $24 \%$ \\
\hline 4 & Bakat & 0,0846 & $8 \%$ & Total & 1,0000 & $100 \%$ \\
\hline \multicolumn{3}{|c|}{ Total } & 1,0000 & $100 \%$ & & & \\
\hline
\end{tabular}

Sumber : Olah Data (2020)
Dari hasil perhitungan tabel-tabel diatas didapatkan urutan prioritas kriteria pemilihan jurusan yang paling dipilih oleh responden yaitu :

1. Peluang Karir : $46 \%$

2. Saran Orangtua $: 24 \%$

3. Minat $: 21 \%$

4. Bakat $: 8 \%$

Dan didapatkan pula urutan prioritas kriteria pemilihan jurusan yang paling dipilih oleh responden yaitu :

$\begin{array}{lll}\text { 1. } & \text { RPL } & : 42 \% \\ \text { 2. } & \text { MM } & : 33 \% \\ \text { 3. } & \text { AP } & : 24 \%\end{array}$

\subsection{Perhitungan Menggunakan Metode MOORA}

Pada tahapan ini akan dijelaskan mengenai proses perhitungan dengan menggunakan metode MOORA dalam pengambilan keputusan pemilihan jurusan pada SMK Tri Dharma 2 Bogor. Tahapan tahapan dalam penerapan dengan menggunakan metode MOORA adalah sebagai berikut :

1. Menentukan Jenis dan Bobot pada setiap Kriteria.

Pada tahap ini akan dilakukan penentuan jenis dari setiap kriteria, dimana kriteria akan terbagi menjadi dua, yaitu kriteria benefit dan cost.

- Benefit, yaitu jenis kriteria dimana jika nilai semakin besar maka akan semakin baik, dan jika semakin kecil maka bernilai tidak baik

- Cost, yaitu jenis kriteria dimana jika nilai semakin kecil maka akan semakin baik, dan jika semakin besar maka akan bernilai tidak baik.

Pada tabel III.21, akan ditampilkan jenis dan bobot pada setiap kriteria.

Tabel III. 21

\begin{tabular}{|c|c|c|c|}
\hline Jenis & dan & Bobot & Kriteria \\
\hline No & Nama Kriteria & Nilai Bobot $\left(W_{j}\right)$ & Kriteria \\
\hline 1 & Minat & 0.25 & Benefit \\
\hline 2 & Bakat & 0.15 & Benefit \\
\hline 3 & Saran Orangtua & 0.35 & Benefit \\
\hline 4 & Peluang Karir & 0.45 & Benefit \\
\hline
\end{tabular}

Sumber : Olah Data (2020)

2. Memasukkan nilai kriteria pada setiap alternatif dari responden yang akan diuji.

Tabel III.22

Nilai Kriteria Untuk Setiap Alternatif

\begin{tabular}{|c|c|c|c|c|}
\hline \multirow{2}{*}{ Alternatif } & \multicolumn{5}{|c|}{ Nama Kriteria } \\
\cline { 2 - 5 } & Minat & Bakat & Saran Orangtua & Peluang Karir \\
\hline AP & 70 & 60 & 70 & 70 \\
\hline MM & 80 & 70 & 90 & 80 \\
\hline RPL & 90 & 80 & 80 & 90 \\
\hline Optimum & Max & Max & Max & Max \\
\hline
\end{tabular}

JISICOM (Journal of Information System, Informatics and Computing)

http://journal.stmikjayakarta.ac.id/index.php/jisicom Telp.+62-21-3905050, e-mail:jisicom@stmikjayakarta.ac.id, jisicom2017@gmail.com 
Sumber : Olah Data (2020)

3. Membuat Matriks Keputusan.

Merubah nilai kriteria menjadi matriks keputusan. Matriks keputusan berfungsi sebagai pengukuran kinerja dari alternatif ke-i pada atribut ke-j, m adalah jumlah alternatif dan $\mathrm{n}$ adalah jumlah atribut. Kemudian sistem rasio dikembangkan dimana setiap kinerja dari sebuah alternatif pada sebuah atribut dibandingkan dengan penyebut yang merupakan wakil untuk semua alternatif dari atribut tersebut, berikut adalah perubahan nilai kriteria menjadi sebuah matriks keputusan :

Keterangan :

$$
X=\left[\begin{array}{rrr}
X 11 & X 12 & X 1 n \\
X 21 & X 22 & X 2 n \\
X m 1 & X m 2 & X m n
\end{array}\right]
$$

$x_{i j} \quad:$ Respon alternative $\mathrm{j}$ pada kriteria $\mathrm{i}$

$i \quad: 1,2,3, \ldots, \mathrm{n}$ adalah nomor urutan kriteria

$j \quad: 1,2,3, \ldots, \mathrm{n}$ adalah nomor urutan alternatif

X : Matriks Keputusan

Tabel III.23

Nilai Matriks Keputusan

\begin{tabular}{|c|c|c|c|c|}
\hline \multirow{2}{*}{ Alternatif } & \multicolumn{4}{|c|}{ Nama Kriteria } \\
\cline { 2 - 5 } & Minat & Bakat & Saran Orangtua & Peluang Karir \\
\hline AP & 70 & 60 & 70 & 70 \\
\hline MM & 80 & 70 & 90 & 80 \\
\hline RPL & 90 & 80 & 80 & 90 \\
\hline
\end{tabular}

Sumber : Olah Data (2020)

Matriks keputusan dari proses pengolahan data pada penelitian ini, sebagai berikut:

$$
X i j=\left[\begin{array}{cccc}
70 & 60 & 70 & 70 \\
80 & 70 & 90 & 80 \\
90 & 80 & 80 & 90
\end{array}\right]
$$

4. Membuat Matriks Normalisasi.

Normalisasi bertujuan untuk menyatukan setiap elemen matriks sehingga elemen pada matriks memiliki nilai yang seragam. Normalisasi pada MOORA dapat dihitung menggunakan persamaan sebagai berikut.

Keterangan :

$$
X *_{i j}=\frac{x_{i j}}{\sqrt{\sum_{j=1}^{m} x_{i j}^{2}}}
$$

$x_{i . j} \quad:$ matriks alternatif $\mathrm{j}$ pada kriteria $\mathrm{i}$

$i \quad: 1,2,3, \ldots, \mathrm{n}$ adalah nomor urutan kriteria $j \quad: 1,2,3, \ldots, \mathrm{n}$ adalah nomor urutan alternatif $x^{*}{ }_{i . j} \quad$ : Matriks Normalisasi kriteria i pada alternatif $\mathrm{j}$

Berikut perhitungan detail matriks normalisasi untuk setiap kriteria pada setiap alternatifnya.
Normalisasi Matriks dari Kriteria 1 (C1)

1) Normalisasi Matriks (1,1) - Kriteria 1 (C1), Alternatif 1 (A1)

$$
\begin{gathered}
X *_{1.1}=\frac{70}{\sqrt{70^{2}+80^{2}+90^{2}}} \\
X *_{1.1}=\frac{70}{\sqrt{19.400}} \\
X *_{1.1}=\frac{70}{139.283} \\
X *_{1.1}=0.5025
\end{gathered}
$$

2) Normalisasi Matriks $(1,2)$ - Kriteria 1 (C1), Alternatif 2 (A2)

$$
\begin{gathered}
X *_{1.2}=\frac{80}{\sqrt{70^{2}+80^{2}+90^{2}}} \\
X *_{1.2}=\frac{80}{\sqrt{19.400}} \\
X *_{1.2}=\frac{80}{139.283} \\
X *_{1.2}=0.5743
\end{gathered}
$$

3) Normalisasi Matriks (1,3) - Kriteria 1 (C1), Alternatif 3 (A3)

$$
\begin{gathered}
X *_{1.3}=\frac{90}{\sqrt{70^{2}+80^{2}+90^{2}}} \\
X *_{1.3}=\frac{90}{\sqrt{19.400}} \\
X *_{1.3}=\frac{90}{139.283} \\
X *_{1.3}=0.6461
\end{gathered}
$$

Normalisasi Matriks dari Kriteria 2 (C2)

1) Normalisasi Matriks (2,1) - Kriteria 2 (C2), Alternatif 1 (A1)

$$
\begin{gathered}
X *_{2.1}=\frac{60}{\sqrt{60^{2}+70^{2}+80^{2}}} \\
X *_{2.1}=\frac{60}{\sqrt{14.900}} \\
X *_{2.1}=\frac{60}{122.065} \\
X *_{2.1}=0.4915
\end{gathered}
$$

2) Normalisasi Matriks $(2,2)$ - Kriteria 2 (C2), Alternatif 2 (A2)

$$
\begin{gathered}
X *_{2.2}=\frac{70}{\sqrt{60^{2}+70^{2}+80^{2}}} \\
X *_{2.2}=\frac{70}{\sqrt{14.900}} \\
X *_{2.2}=\frac{70}{122.065} \\
X *_{2.2}=0.5734
\end{gathered}
$$

JISICOM (Journal of Information System, Informatics and Computing) http://journal.stmikjayakarta.ac.id/index.php/jisicom Telp.+62-21-3905050, e-mail:jisicom@stmikjayakarta.ac.id, jisicom2017@gmail.com 
3) Normalisasi Matriks (2,3) - Kriteria 2 (C2), Alternatif 3 (A3)

$$
\begin{gathered}
X *_{2.3}=\frac{80}{\sqrt{60^{2}+70^{2}+80^{2}}} \\
X *_{2.3}=\frac{80}{\sqrt{14.900}} \\
X *_{2.3}=\frac{80}{122.065} \\
X *_{2.3}=0.6553
\end{gathered}
$$

Normalisasi Matriks dari Kriteria 3 (C3)

1) Normalisasi Matriks (3,1) - Kriteria 3 (C3), Alternatif 1 (A1)

$$
\begin{gathered}
X *_{3.1}=\frac{70}{\sqrt{70^{2}+90^{2}+80^{2}}} \\
X *_{3.1}=\frac{70}{\sqrt{19.400}} \\
X *_{3.1}=\frac{70}{139.283} \\
X *_{3.1}=0.5025
\end{gathered}
$$

2) Normalisasi Matriks $(3,2)$ - Kriteria 3 (C3), Alternatif 2 (A2)

$$
\begin{gathered}
X *_{3.2}=\frac{90}{\sqrt{70^{2}+90^{2}+80^{2}}} \\
X *_{3.2}=\frac{90}{\sqrt{19.400}} \\
X *_{3.2}=\frac{90}{139.283} \\
X *_{3.2}=0.6461
\end{gathered}
$$

3) Normalisasi Matriks (3,3) - Kriteria 3 (C3), Alternatif 3 (A3)

$$
\begin{gathered}
X *_{3.3}=\frac{80}{\sqrt{70^{2}+90^{2}+80^{2}}} \\
X *_{3.3}=\frac{80}{\sqrt{19.400}} \\
X *_{3.3}=\frac{80}{139.283} \\
X *_{3.3}=0.5743
\end{gathered}
$$

Normalisasi Matriks dari Kriteria 4 (C4)

1) Normalisasi Matriks (4,1) - Kriteria 2 (C4), Alternatif 1 (A1)

$$
\begin{gathered}
X *_{4.1}=\frac{70}{\sqrt{70^{2}+80^{2}+90^{2}}} \\
X *_{4.1}=\frac{70}{\sqrt{19.400}} \\
X *_{4.1}=\frac{70}{139.283} \\
X *_{4.1}=0.5025
\end{gathered}
$$

2) Normalisasi Matriks (4,2) - Kriteria 2 (C4), Alternatif 2 (A2)

$$
\begin{gathered}
X *_{4.2}=\frac{80}{\sqrt{70^{2}+80^{2}+90^{2}}} \\
X *_{4.2}=\frac{80}{\sqrt{19.400}} \\
X *_{4.2}=\frac{80}{139.283} \\
X *_{4.2}=0.5743
\end{gathered}
$$

3) Normalisasi Matriks (4,3) - Kriteria 2 (C4), Alternatif 3 (A3)

$$
\begin{gathered}
X *_{4.3}=\frac{90}{\sqrt{70^{2}+80^{2}+90^{2}}} \\
X *_{4.3}=\frac{90}{\sqrt{19.400}} \\
X *_{4.3}=\frac{90}{139.283} \\
X *_{4.3}=0.6461
\end{gathered}
$$

Dari perhitungan nilai normalisasi di atas, maka akan diperoleh matriks normalisasi $\left(\mathrm{x}^{*}\right)$, sebagai berikut :

$$
\mathrm{x}^{*}=\left[\begin{array}{llll}
0.5025 & 0.4915 & 0.5025 & 0.5025 \\
0.5743 & 0.5734 & 0.6461 & 0.5743 \\
0.6461 & 0.6553 & 0.5743 & 0.6461
\end{array}\right]
$$

5. Menghitung Optimalisasi Nilai Atribut.

Untuk menandakan bahwa sebuah atribut lebih penting itu bisa dikalikan dengan bobot yang sesuai (koefisien signifikasi). Nilai optimasi dihitung untuk setiap alternatif yang diberikan, yang merupakan jumlah perkalian bobot kriteria dengan nilai atribut maksimum $(\max )$ yaitu nilai atribut bertipe benefit dikurangi dengan jumlah perkalian dari bobot kriteria dengan milai atribut minimum (min) yaitu nilai atribut bertipe cost. Perhitungan nilai optimasi multiobjektif MOORA jika dirumuskan menjadi :

$$
Y i=\sum_{j=1}^{g} W_{j} X^{*} i j-\sum_{j=g+1}^{n} W_{j} X^{*} i j
$$

Keterangan :

$i \quad: 1,2,3, \ldots, \mathrm{g}$ adalah kriteria dengan status maximized

$j \quad: g+1, g+2, g+3, \ldots, n$ adalah kriteria dengan status minimized

$w_{j} \quad$ : bobot terhadap alternatif $\mathrm{j}$

$Y_{i} \quad$ : nilai yang sudah di normalisasi dari alternatif $\mathrm{j}$ terhadap semua atribut

Hasil perhitungan nilai optimasi dalam penelitian ini sebagai berikut :

Perhitungan nilai optimasi untuk alternatif $1\left(A^{*} 1\right)$

\section{JISICOM (Journal of Information System, Informatics and Computing)}

http://journal.stmikjayakarta.ac.id/index.php/jisicom Telp.+62-21-3905050, e-mail:jisicom@stmikjayakarta.ac.id, jisicom2017@gmail.com 


$$
\begin{gathered}
A^{*} 1=\left(x^{*}{ }_{1.1(\max )} \cdot w_{1}+x^{*}{ }_{1.2(\max )} \cdot w_{2}\right. \\
+x^{*}{ }_{1.3(\max )} \cdot w_{3} \\
\left.+x^{*}{ }_{1.4(\max )} \cdot w_{4}\right) \\
A^{* 1}=\left(0.5025^{*} 0.25+0.4915^{*} 0.15\right. \\
\left.+0.5025^{*} 0.35+0.5025^{*} 0.45\right) \\
A^{*} 1=0.1256+0.0737+0.1758+0.2261 \\
A^{*} 1=0.6012
\end{gathered}
$$

Perhitungan nilai optimasi untuk alternatif $2\left(\mathrm{~A}^{*} 2\right)$

$$
\begin{gathered}
A^{*} 2=\left(x_{2.1(\max ) \cdot}^{*} w_{1}+x^{*}{ }_{2.2(\max )} \cdot w_{2}\right. \\
+x^{*}{ }_{2.3(\max )} \cdot w_{3} \\
\left.+x^{*}{ }_{2.4(\max )} \cdot w_{4}\right) \\
A^{*} 2=\left(0.5743^{*} 0.25+0.5734^{*} 0.15\right. \\
\left.+0.6461^{*} 0.35+0.5743^{*} 0.45\right) \\
A^{*} 2=0.1435+0.0860+0.2261+0.2584 \\
A^{*} 2=0.7140
\end{gathered}
$$

Perhitungan nilai optimasi untuk alternatif $3\left(\mathrm{~A}^{*} 3\right)$

$$
\begin{gathered}
A^{*} 3=\left(x^{*}{ }_{3.1(\max ) \cdot w_{1}+x^{*}{ }_{3.2(\max )} \cdot w_{2}}+x^{*}{ }_{3.3(\max ) \cdot w_{3}}\right. \\
\left.+x^{*}{ }_{3.4(\max ) \cdot w_{4}}\right) \\
A^{*} 3=\left(0.6461^{*} 0.25+0.6553^{*} 0.15\right. \\
\left.+0.5743^{*} 0.35+0.6461^{*} 0.45\right) \\
A^{*} 3=0.1615+0.0982+0.2010+0.2907 \\
A^{*} 3=0.7514
\end{gathered}
$$

6. Hasil Perangkingan

Langkah terakhir setelah melakukan perhitungan nilai optimasi pada setiap alternatif untuk setiap kriteria, maka hasilnya dapat diurutkan mulai dari yang terbesar sampai yang terkecil. Dimana hasil perhitungan optimasi dari alternatif yang terbesar menunjukkan alternatif yang terpilih, sedangkan nilai optimasi yang terendah menunjukkan hasil yang terburuk dari hasil data yang diolah. Dari perhitungan optimasi yang telah dilakukan, maka hasilnya dapat dilihat pada tabel berikut :

Tabel III.24

Hasil Perangkingan

\begin{tabular}{|c|c|c|}
\hline Alternatif & Nilai Optimasi(Yi) & Rangking \\
\hline AP & 0.6012 & 3 \\
\hline MM & 0.7140 & 2 \\
\hline RPL & 0.7514 & 1 \\
\hline
\end{tabular}

Sumber : Olah Data (2020)

Dari hasil akhir perhitungan optimasi, dapat diambil kesimpulan bahwa alternatif 3 (A3), RPL dengan nilai optimasi sebesar 0.7514 , merupakan nilai optimasi terbesar, yang menunjukkan alternatif yang terpilih, berikutnya alternatif 2 (A2) yaitu MM dengan nilai optimasi sebesar 0.7140, sedangkan nilai optimasi terendah adalah alternatif 1 (A1), AP dengan nilai optimasi sebesar 0.145.

Berdasarkan hasil yang di dapat, maka dapat diambil kesimpulan bahwa metode MOORA dapat digunakan dalam pengambilan keputusan pemilihan jurusan pada sekolah SMK Tri Dharma 2 Bogor.

\subsection{Hasil Pembahasan}

Dari hasil akhir perhitungan optimasi, dapat diambil kesimpulan bahwa alternatif RPL dengan nilai optimasi menggunakan metode AHP sebesar 0,4225 dan metode MOORA sebesar 0,7514 merupakan nilai optimasi terbesar, yang menunjukan alternatif terpilih, pada urutan kedua yaitu alternatif $\mathrm{MM}$ dengan nilai optimasi menggunakan metode AHP sebesar 0,3327 dan metode MOORA sebesar 0,7140, sedangkan nilai optimasi terendah yaitu AP dengan optimasi menggunakan metode AHP sebesar 0,2448 dan metode MOORA sebesar 0,6012. Hasil perhitungan diatas dengan menggunakan metode AHP dan MOORA ditampilkan dalam bentuk grafik dibawah ini.

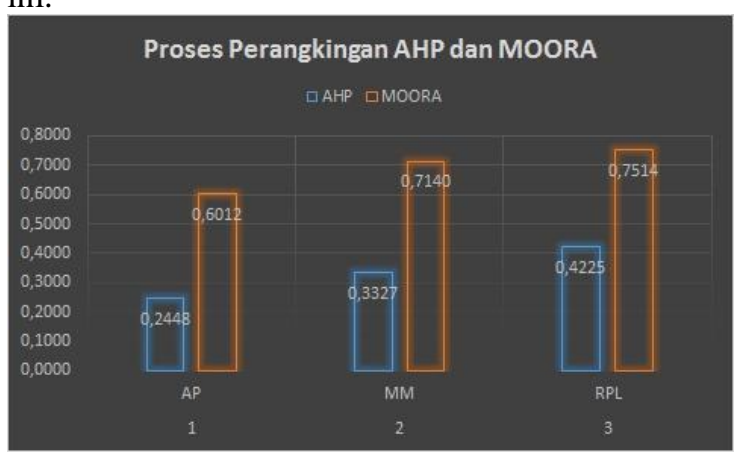

Sumber: Olah Data (2020)

Gambar III.3 Grafik Perangkingan

\section{IV.KESIMPULAN}

Dari hasil yang didapat, maka dapat diambil kesimpulan bahwa metode AHP dan MOORA dapat digunakan dalam pengambilan keputusan pemilihan jurusan pada SMK Tri Dharma 2 Bogor dan juga minat, bakat, saran orangtua dan peluang karir mempengaruhi dalam pemilihan jurusan ini yang berarti $\mathrm{H} 1, \mathrm{H} 2$ dan $\mathrm{H} 3$ diterima dan $\mathrm{H} 0$ ditolak..

JISICOM (Journal of Information System, Informatics and Computing)

http://journal.stmikjayakarta.ac.id/index.php/jisicom Telp.+62-21-3905050, e-mail:jisicom@stmikjayakarta.ac.id, jisicom2017@gmail.com 


\section{REFERENSI}

[1] M. Rahmayu and R. K. Serli,

"Simetris : jurnal teknik mesin, elektro dan ilmu komputer.," Simetris J. Tek. Mesin, Elektro dan Ilmu Komput., vol. 9, no. 1, pp. 551-564, 2018, [Online]. Available:

https://jurnal.umk.ac.id/index.php/sime t/article/view/2022.

[2] G. Yanti, S. Pahu, and L. J. Susanto, "DENGAN METODE

ANALYTHICAL HIERARCHY

PROCESS ( STUDI KASUS : SMK

GANESHA LAMPUNG TIMUR )," $J$.

Manag. Sist. Inf. dan Teknol., vol. 2,

no. 2, p. 84, 2018.

[3] F. Frieyadie and S. M. Ramadhan,

"Penerapan Metode AHP Untuk

Membantu Siswa Memilih Jurusan

Yang Tepat Di SMK," J. RESTI

(Rekayasa Sist. dan Teknol. Informasi), vol. 2, no. 3, pp. 662-667, 2018, doi: 10.29207/resti.v2i3.396.

[4] T. Hasanah, H. J. S.Sitio, and I.-

Parlina, "Sistem Pendukung Keputusan

Pemilihan Jurusan Pada Yayasan

Muhammad Nasir dengan

Menggunakan Metode MOORA," $J$.

Informatics Telecommun. Eng., vol. 2, no. 2 , p. 128, 2019, doi:

10.31289/jite.v2i2.2161.

[5] A. Y. Malik and T. Haryanti,

"PENERAPAN METODE

ANALYTICAL HIERARCHY

PROCESS ( AHP ) UNTUK SISTEM

PENDUKUNG KEPUTUSAN

PEMILIHAN PROGRAM,"

Penerapan Metod. Anal. Hierarchy
Process untuk Sist. Pendukung

Keputusan pemilihan Progr., vol. 14, no. 1, pp. 123-130, 2018.

[6] I. Harmaizar Z, Menggali Potensi Wirausaha. Bekasi: Anugerah Prakasa, CV Dian, 2006.

[7] Istijanto, Aplikasi Praktis Riset Pemasaran Cara Praktis Meneliti Konsumen Dan Pesaing. Jakarta: Gramedia Pustaka Utama, 2010.

[8] B. Chandra, PENGANTAR STATISTIK KESEHATAN. Jakarta: Penerbit Buku Kedokteran EGC, 1995.

[9] D. Dolet Unaradjan, Metode Penelitian Kuantitatif. Jakarta: Penerbit Unika Atma Jaya, 2019.

[10] D. H. Pratiwi, Buku Ajar Sistem Pendukung Keputusan. Yogyakarta: Deepublish, 2016.

[11] D. Nofriansyah and P. D. S. Defit, Multi Criteria Decision Making (MCDM) pada Sistem Pendukung Keputusan. Yogyakarta: Penerbit Deepublish, 2017.

JISICOM (Journal of Information System, Informatics and Computing)

http://journal.stmikjayakarta.ac.id/index.php/jisicom Telp.+62-21-3905050, e-mail:jisicom@stmikjayakarta.ac.id, jisicom2017@gmail.com 